Revista Brasil. Bot., V.28, n.3, p.635-649, jul.-set. 2005

\title{
Anatomia foliar de Tillandsia L. (Bromeliaceae) dos Campos Gerais, Paraná, Brasil
}

\author{
VERA LUCIA SCATENA ${ }^{1,3}$ e SIMONE SEGECIN ${ }^{2}$
}

(recebido: 30 de dezembro de 2004; aceito: 6 de outubro de 2005)

\begin{abstract}
Leaf anatomy of Tillandsia L. (Bromeliaceae) from "Campos Gerais", Paraná, Brazil). The leaf anatomy of Tillandsia crocata (E. Morren) Baker, T. gardneri Lindl., T. geminiflora Brongn., T. linearis Vell., T. lorentziana Griseb., T. mallemontii Glaziou ex Mez, T. recurvata L., T. streptocarpa Baker, T. stricta Soland ex Sims, T. tenuifolia L., T. usneoides L., and Tillandsia sp. were studied. They occur in the "Campos Gerais", State of Paraná, southern Brazil. In surface view epidermis presents cells with linear to sinuous anticlinal walls, silica bodies and scales covering anomocytic stomata. Epidermis and first hypodermal layer are lignified. Transversal view reveals below surface stomata, aquiiferous parenchyma, longitudinal air canals and collateral vascular bundles with double sheath. These anatomical features are xeromorphic and usually considered as an adaptation to the epiphytic habit of the atmospheric Tillandsia. Moreover, they could be also used for diagnostic purposes. Leaf shape in cross section, cuticle ornamentation, epidermal scale structures, thickening of the epidermal wall cells, stomata distribution, structure and distribution of the aqüiferous parenchyma cells, presence of air canals, and size of vascular bundle could help the taxonomic delimitation of the species within the genus.
\end{abstract}

Key words - Bromeliaceae, canopy, epiphytes, leaf anatomy, Tillandsia

RESUMO - (Anatomia foliar de Tillandsia L. (Bromeliaceae) dos Campos Gerais, Paraná, Brasil). Foi estudada a anatomia foliar de Tillandsia crocata (E. Morren) Baker, T. gardneri Lindl., T. geminiflora Brongn., T. linearis Vell., T. lorentziana Griseb., T. mallemontii Glaziou ex Mez, T. recurvata L., T. streptocarpa Baker, T. stricta Soland ex Sims, T. tenuifolia L. T. usneoides L. e Tillandsia sp., dos Campos Gerais, Paraná, Brasil. Em vista frontal a epiderme apresenta células com paredes lineares até sinuosas, corpos silicosos e escamas epidérmicas que protegem os estômatos anomocíticos. A epiderme e o primeiro estrato da hipoderme apresentam células lignificadas na maioria das espécies. Em secção transversal observa-se estômatos que ocorrem um pouco abaixo do nível das demais células da epiderme; presença de parênquima aqüífero; canais de ar longitudinais e feixes vasculares colaterais circundados por bainha dupla. Essas estruturas anatômicas são xeromórficas e usualmente consideradas como adaptações ao hábito epifítico das Tillandsia atmosféricas. Além disso, elas poderiam também ser usadas com finalidades diagnósticas para as espécies. Forma do limbo da folha em secção transversal, ornamentação da cutícula, estrutura das escamas epidérmicas, espessamento das paredes das células epidérmicas, distribuição dos estômatos, estrutura e distribuição das células do parênquima aqüífero, presença de canais de ar e tamanho de feixes vasculares são caracteres que podem auxiliar na delimitação taxonômica das espécies dentro do gênero.

Palavras-chave - anatomia foliar, Bromeliaceae, dossel, epífitas, Tillandsia

\section{Introdução}

O histórico taxonômico de Bromeliaceae revela que o número de gêneros e espécies varia consideravelmente, de 37 a 57 gêneros e de 1.400 a 2.070 espécies (Tomlinson 1969, Smith \& Dows 1979, Cronquist 1981, Dahlgren et al. 1985, Leme \& Marigo 1993, Judd et al. 1999, Stevens 2001, Barfuss et al. 2005). Todos esses autores concordam quanto à distribuição geográfica das

\footnotetext{
1. Universidade Estadual Paulista, Instituto de Biociências, Departamento de Botânica, Caixa Postal 199, Av. 24 A, n. 1515, Bela Vista, 13506-900 Rio Claro, São Paulo, Brasil.

2. Rua Sebastião Satuca n. 59, Caieiras, 83280-000 Guaratuba, Paraná, Brasil.

3. Autor para correspondência: vscatena@ @rc.unesp.br
}

espécies, que ocorrem nas Américas do Sul e Central, com exceção de Pitcairnia feliciana (A. Chevalier) Harms \& Mildbraed, que ocorre na África Ocidental.

Os representantes de Bromeliaceae encontram-se divididos em três subfamílias: Pitcairnioideae, Bromelioideae e Tillandsioideae (Tomlinson 1969, Smith \& Downs 1974, 1977, 1979, Cronquist 1981, Dahlgren et al. 1985, Judd et al. 1999, Stevens 2001). A maioria das Tillandsioideae é epífita, adaptada a ambientes secos e possui forma de crescimento altamente especializada, com escamas epidérmicas foliares que são capazes de absorver água e nutrientes (Tomlinson 1969, Benzing 1976, Braga 1977).

Algumas espécies de Tillandsia, como por exemplo Tillandsia usneoides, foram utilizadas como bioindicadores da poluição do ar na cidade de São Paulo, Brazil, por Figueiredo et al. $(2001,2004)$ e também no 
biomonitoramento atmosférico, por Amado et al. (2002).

Entre os estudos anatômicos de Bromeliaceae devem ser destacados o de Robinson (1969), que utiliza a anatomia foliar para delimitar as espécies dos gêneros Connelia, Cottendorfia e Navia, e o de Tomlinson (1969), que reúne informações sobre estudos anatômicos disponíveis na literatura.

Segundo Braga (1977) a variabilidade estrutural das folhas de Bromeliaceae constitui importante fonte de dados que suscitam especulações tanto de cunho filogenético e ontogenético, quanto fisiológico, ecológico e taxonômico. A autora apresenta a anatomia foliar de seis espécies de Bromeliaceae de uma campina da Amazônia Central.

Estudos realizados com as escamas epidérmicas absorventes das folhas de Bromeliaceae mencionam sua capacidade de absorver água e nutrientes (Haberlandt 1914, Solereder \& Meyer 1929, Kraus 1948, Tomlinson 1969). A comprovação de que as escamas epidérmicas de determinadas espécies de Bromeliaceae realmente absorvem água e nutrientes coube a Benzing (1970, 1976), Benzing et al. (1976) e Benzing \& Renfrow (1980).

Baseando-se no estudo comparativo das escamas epidérmicas foliares de 100 táxons de Bromeliaceae, Strehl (1983) apresenta hipóteses sobre as prováveis linhas filogenéticas da família. Sajo et al. (1998) analizam 68 espécies de diferentes gêneros de Bromeliaceae visando principalmente a delimitação taxonômica do gênero Nidularium e de gêneros afins. Proença \& Sajo (2004) estudam a estrutura foliar de espécies de Aechmea do Estado de São Paulo e apresentam uma chave de identificação das mesmas baseada nos caracteres anatômicos.

Segundo Judd et al. (1999), o gênero Tillandsia apresenta 450 espécies e, segundo Stevens (2001), cerca de 540 espécies. Na região dos Campos Gerais, Paraná, Tillandsia é o gênero melhor representado para a família Bromeliaceae, com doze espécies, todas elas epífitas de afloramentos rochosos, matas ciliares e capões. Segecin \& Scatena (2004a, b) estudam a anatomia de escapos, rizomas e raízes de espécies de Tillandsia dessa região e relacionam os caracteres anatômicos com a adaptação das espécies ao hábito epifítico. Apresentam também uma chave de identificação das espécies baseada nos caracteres anatômico dos escapos.

Procurando subsidiar a taxonomia das Tillandsia que ocorrem nos Campos Gerais do Paraná, este trabalho tem como objetivo caracterizar anatomicamente as folhas das doze espécies que aí ocorrem e interpretar as possíveis adaptações ao hábito epifítico através das estruturas anatômicas.

\section{Material e métodos}

As espécies de Tillandsia foram coletadas na região dos Campos Gerais, no Paraná, nas áreas de preservação ambiental, nos Parques Estaduais de Vila Velha e Guartelá e no Parque Municipal São Jorge. Parte do material coletado foi herborizado para posterior identificação, enquanto o material restante foi fixado em FAA 50 (Johansen 1940) e estocado em álcool 70\%, para realização dos estudos anatômicos das folhas.

As exsicatas estão depositadas no Herbário da Universidade Estadual de Ponta Grossa (HUEPG) e no Herbarium Rioclarense (HRCB), sob os números: Tillandsia crocata (E. Morren) Baker, HUEPG 4873, HRCB 27836; Tillandsia gardneri Lindl., HUEPG 4465, HRCB 33090; Tillandsia geminiflora Brongn., HUEPG 4876, HRCB 18836; Tillandsia linearis Vell., HUEPG 4874, HRCB 27832; Tillandsia lorentziana Griseb., HUEPG 4426, HRCB 30166; Tillandsia mallemontii Glaziou ex Mez., HUEPG 4390, HRCB 27833; Tillandsia recurvata L., HUEPG 4286, HRCB 27837; Tillandsia streptocarpa Baker, HUEPG 4420, HRCB 27829; Tillandsia stricta Soland. ex Sims, HUEPG 4238, HRCB 27835; Tillandsia tenuifolia L., HUEPG 4875, HRCB 27830; Tillandsia usneoides L., HRCB 27834; Tillandsia sp., HUEPG 3673.

Para o estudo anatômico foram feitas secções à mão livre, com auxílio de lâminas de barbear, na região mediana das folhas adultas de pelo menos três indivíduos diferentes de cada espécie. As secções foram submetidas ao processo de dupla coloração com fucsina básica e azul de astra (Roeser 1962) e montadas em lâminas semipermanentes. Para o estudo da epiderme, em vista frontal, foram realizadas secções paradérmicas à mão livre.

Algumas secções de material fresco foram utilizadas para os testes microquímicos, empregando-se solução de floroglucina em meio ácido (Johansen 1940) para lignina; e solução de azul de metileno (Langeron 1949), para verificar a presença de mucilagem celulósica. Para a caracterização dos corpos de sílica as lâminas foram observadas em contraste de fase e luz polarizada ao microscópio de luz. As convenções adotadas nos esquemas seguiram Tomlinson (1969).

\section{Resultados}

A distribuição espacial dos tecidos das folhas de todas as espécies de Tillandsia estudadas está representada nos diagramas das secções transversais da região mediana (figuras 1-12). A forma do limbo varia desde levemente curvado, como em Tillandsia gardneri Lindl. (figura 2), T. geminiflora Brongn. (figura 3), T. lorentziana Griseb. (figura 5), T. stricta Soland. 


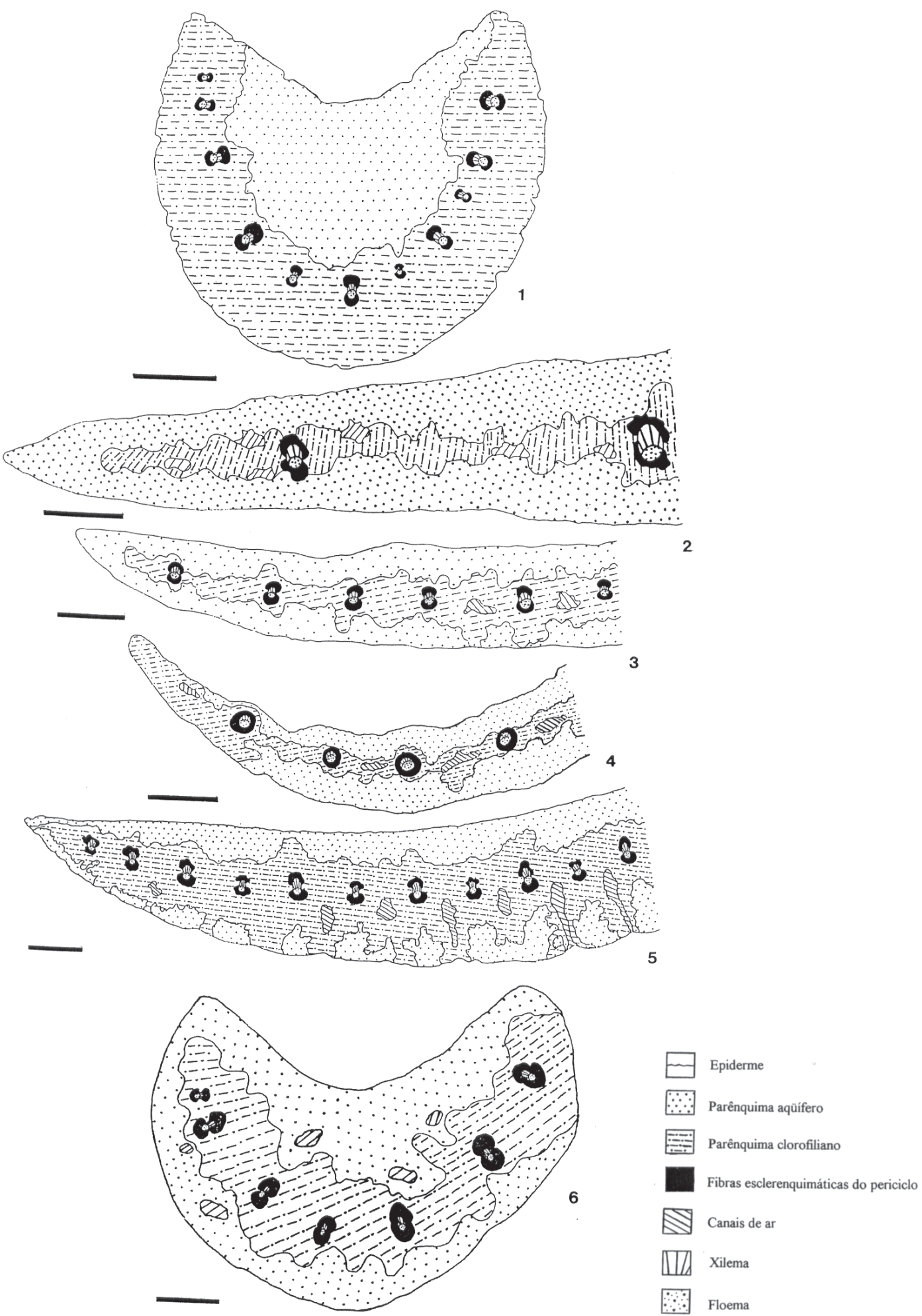

Figuras 1-6. Diagramas de secções transversais da região mediana de folhas: 1. Tillansia crocata. 2. T. gardneri. 3. T. geminiflora. 4. T. linearis. 5. T. lorentziana. 6. T. mallemontii. Barras $=30 \mu \mathrm{m}(1-3,5) ; 20 \mu \mathrm{m}(4) ; 25 \mu \mathrm{m}(6)$.

Figures 1-6. Diagrams from cross sections at median region of the Tillandsia leaves: 1. Tillandsia crocata. 2. T. gardneri. 3. T. geminiflora. 4. T. linearis. 5. T. lorentziana. 6. T. mallemontii. Bars $=30 \mu \mathrm{m}(1-3,5) ; 20 \mu \mathrm{m}(4) ; 25 \mu \mathrm{m}(6)$. 


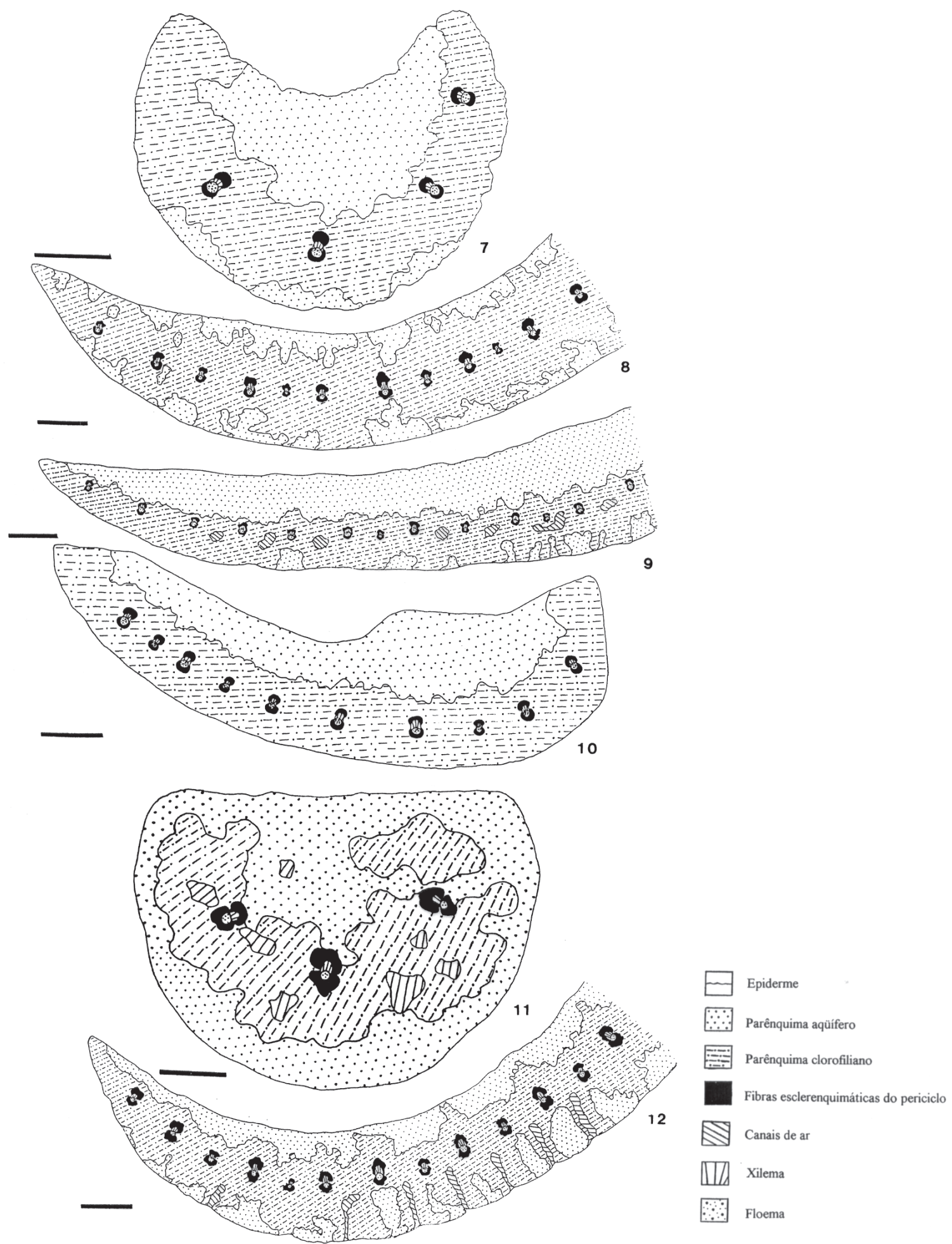

Figuras 7-12. Diagramas de secções transversais da região mediana de folhas. 7. Tillandsia recurvata. 8. T. streptocarpa. 9. T. stricta. 10. T. tenuifolia. 11. T. usneoides. 12. Tillansia sp. Barras $=25 \mu \mathrm{m}(7) ; 30 \mu \mathrm{m}(8-10,12) ; 100 \mu \mathrm{m}(11)$.

Figures 7-12. Diagrams from cross sections at median region of the Tillandsia leaves. 7. Tillandsia recurvata. 8. T. streptocarpa. 9. T. stricta. 10. T. tenuifolia. 11. T. usneoides. 12. Tillansia sp. Bars $=25 \mu \mathrm{m}(7) ; 30 \mu \mathrm{m}(8-10,12) ; 100 \mu \mathrm{m}(11)$. 
(figura 9) e T. tenuifolia L. (figura 10), passando por curvo, em T. linearis Vell. (figura 4), T. streptocarpa Baker (figura 8), e Tillandsia sp. (figura 12), até côncavo-convexo, em T. crocata (E. Morren) Baker (figura 1), T. mallemontii Glaziou ex Nez. (figura 6) e T. recurvata L. (figura 7), e plano-convexo, como em T. usneoides L. (figura 11).

Todas as espécies apresentam: epiderme, parênquima aqüífero, parênquima clorofiliano e sistema vascular circundado total ou parcialmente por fibras. Podem apresentar canais de ar distribuídos no mesofilo (figuras 2-6, 9, 11-12) ou não (figuras 1, 7-8, 10). O parênquima aquífero pode predominar na face adaxial, como em $T$. crocata (figura 1 ), T. recurvata (figura 7 ), T. stricta (figura 9) e T. tenuifolia (figura 10), ou localizar-se em ambas as faces, como nas demais espécies (figuras 2-6, 8, 11-12).

Em vista frontal, todas as espécies de Tillandsia estudadas apresentam as células epídérmicas, de ambas as faces da folha, com formato retangular. Algumas apresentam as paredes aproximadamente retas, como em Tillandsia crocata (figura 13) e T. streptocarpa (figura 22), outras apresentam-nas curvas como em T. gardneri (figuras 14, 16), outras onduladas como em T. mallemontii, T. usneoides e Tillandsia sp. (figuras $23,27,28$, respectivamente), e outras sinuosas como em T. linearis, T. recurvata, e T. lorentziana (figuras $15,20,25$, respectivamente).

Foram observados corpos de sílica nas células epidérmicas de todas as espécies estudadas, como mostrado em T. crocata, T. gardneri, T. mallemontii, T tenuifolia e Tillandsia sp. (figuras 13, 14, 23, 57, 60, respectivamente, cabeças de seta).

Todas as folhas de Tillandsia estudadas apresentam as faces da epiderme recobertas por escamas epidérmicas. Em vista frontal, evidencia-se apenas o escudo das escamas epidérmicas, que exibe quatro células centrais (a), de forma triangular, que se encaixam formando um círculo, com paredes finas. Essas células centrais são circundadas por duas séries de células de forma retangular ou quadrada, com paredes delgadas. A primeira série é constituída de oito células e são denominadas pericentrais (b), a segunda série é constituída de dezesseis células e são denominadas subperiféricas (c). Externamente a essas células estão as células periféricas (d), constituídas de cerca de cinquenta a setenta e quatro células. Essas células periféricas, são alongadas, dispostas radialmente e apresentam paredes finas (figuras 17-19, 21, 26, 29).

O escudo periférico das escamas epidérmicas pode se mostrar simétrico em Tillandsia linearis (figura 17) e T. tenuifolia (figuras 24,26 ) e assimétrico nas demais espécies (figuras 18-19, 21, 29).

Os estômatos apresentam-se distribuídos longitudinalmente e localizam-se na face abaxial da folha, com exceção de $T$. streptocarpa que apresenta estômatos em ambas as faces da epiderme. São anomocíticos (figuras 13, 16, 23, 25) e circundados por células epidérmicas menores, como pode ser observado em Tillandsia crocata (figura 13) e T. mallemontii (figura 23). Os estômatos encontram-se recobertos por células do escudo das escamas epidérmicas, como pode ser observado em T. tenuifolia (figura 24).

A grande maioria das espécies estudadas apresenta células epidérmicas com cutícula sem ornamentação (figuras 53, 60), com exceção de T. streptocarpa que apresenta cristalóides de agregados de cera, constituindo ornamentações em forma de botões (figura 54).

O espessamento das paredes das células epidérmicas pode variar. Algumas espécies apresentam ambas as faces com paredes finas, como Tillandsia gardneri (figura 32), T. geminiflora (figura 33) e T. streptocarpa (figuras 38-39). Outras apresentam-nas levemente espessadas como T. mallemontii (figuras 36, 52), T. recurvata (figuras 37,53 ), $T$. usneoides (figuras 43-44) e Tillandsia sp. (figuras 45, 59-60). As demais espécies estudadas apresentam células epidérmicas de paredes muito espessadas, lignificadas, como $T$. crocata (figuras 30-31, 46), T. linearis (figuras 35, 50-51), T. stricta (figuras 40, 55-56) e T. tenuifolia (figuras 41-42, 57-58). Nessas espécies o espessamento deixa de ocorrer somente na face periclinal externa da parede e a célula apresenta lume muito reduzido (figuras 46, 51- cabeça de seta, 55, 58).

Em $T$. recurvata, $T$. tenuifolia e $T$. gardneri (figuras 37, 41, 48, respectivamente) os estômatos ocorrem no mesmo nível das demais células da epiderme. Nas demais espécies eles ocorrem um pouco abaixo do nível das demais células epidérmicas (figuras 30, 37, 39, 44, 46, 56, 59). A câmara subestomática comunica-se com canais de ar do mesofilo, como pode ser observado em $T$. gardneri (figura 48), T. stricta (figura 56) e Tillandsia sp. (figura 59).

Em secção transversal da folha, observa-se a inserção da escama, que apresenta células basais, pedículo e células do escudo (figuras 51-52). As células basais e as do pedículo são vivas. As células periféricas do escudo são mortas e encaixam-se com as da escama vizinha, justapostas, formando um revestimento na epiderme foliar, em toda a extensão do limbo, como pode-se observar em T. crocata (figura 31) e Tillandsia sp. (figura 45). 

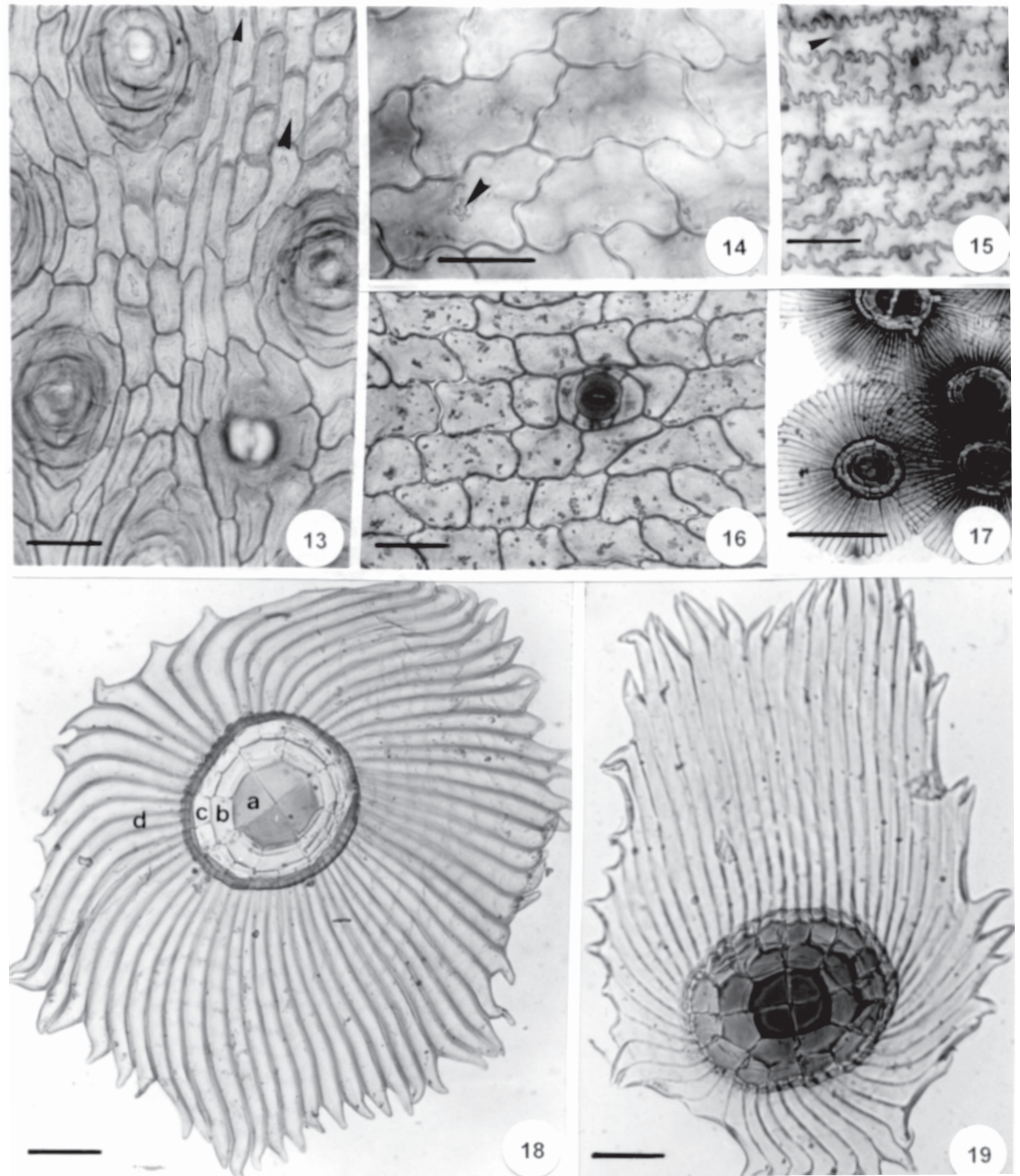

Figuras 13-19. Vista frontal da epiderme foliar. 13. Tillandsia crocata: face abaxial, cabeças-de-setas: corpos de sílica. Figuras 14, 16, 18. T. gardneri: face adaxial, cabeça-de-seta: corpos de sílica (figura 14); face abaxial (figura 16); escama (figura 18). Figuras 15, 17. T. linearis: face abaxial, cabeça-de-seta: corpos de sílica (figura 15); escamas epidérmicas (figura 17). Figura 19. T. lorentziana: escama. ( $\mathrm{a}=$ células centrais; $\mathrm{b}=$ células pericentrais; $\mathrm{c}=$ células subperiféricas; $\mathrm{d}=$ células periféricas do escudo). Barras $=50 \mu \mathrm{m}(13-16,18-19) ; 200 \mu \mathrm{m}$ (17).

Figures 13-19. Epidermis leaf surface view. 13. Tillandsia crocata: abaxial epidermis, arrowheads: silica bodies. Figures 14, 16, 18. T. gardneri: adaxial epidermis, arrowhead: silica bodies (figure 14); abaxial epidermis (figure 16); scale (figure 18). Figures 15, 17. T. linearis: abaxial epidermis, arrowhead: silica bodies (figure 15); scales (figure 17). Figure 19. T. lorentziana: scale. $(\mathrm{a}=$ central cells $; \mathrm{b}=$ pericentral cells; $\mathrm{c}=$ subperipheral cells; $\mathrm{d}=$ peripheral cells $)$. Bars $=50 \mu \mathrm{m}(13-16,18-19) ; 200 \mu \mathrm{m}(17)$. 


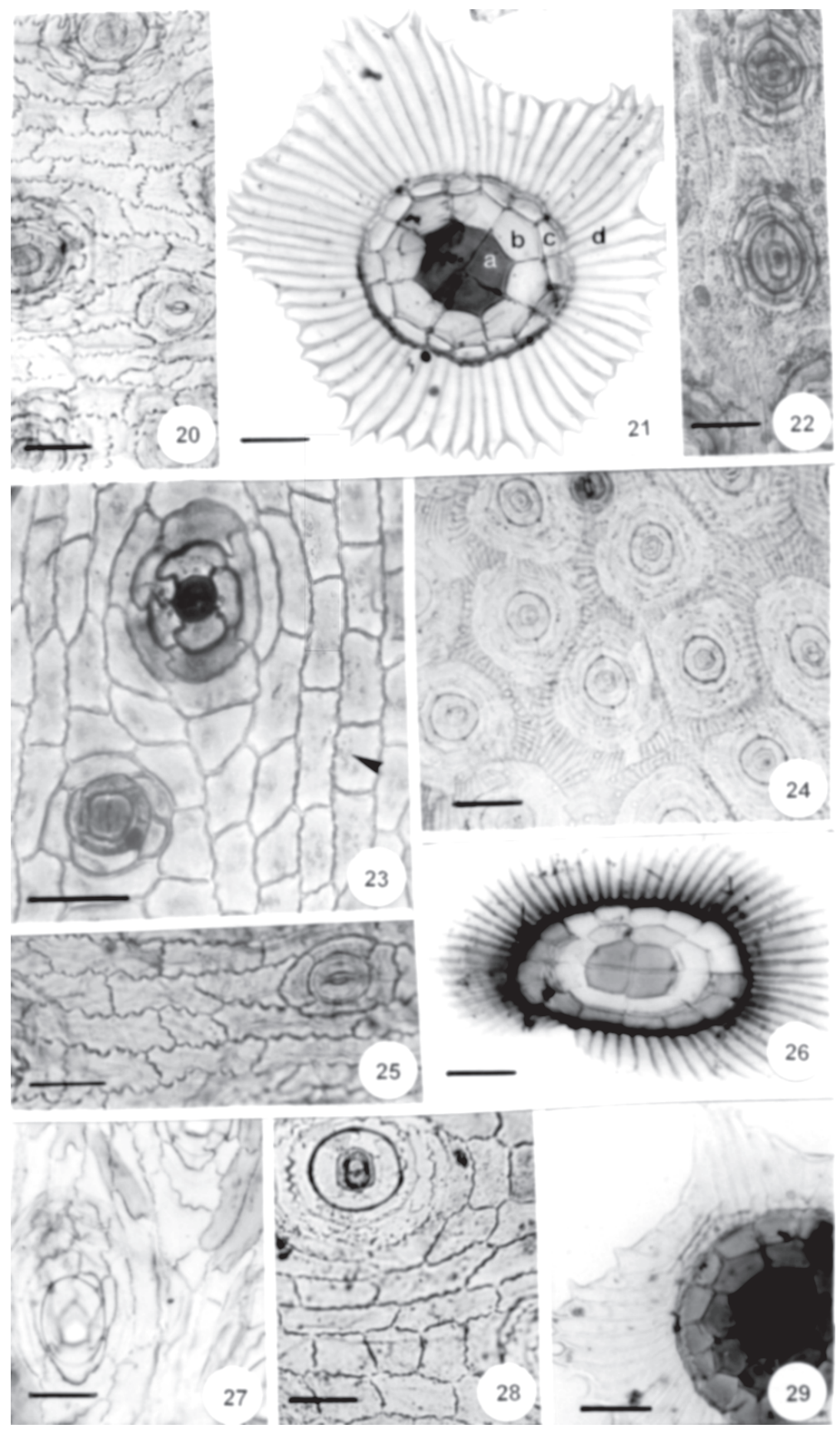

Figuras 20-29. Vista frontal da epiderme foliar. 20-21. Tillandsia recurvata: face abaxial (figura 20); escama (figura 21). 22. T. streptocarpa: face abaxial. 23. T. mallemontii: face abaxial, cabeça-de-seta: corpos de sílica. Figuras 24, 26. T. tenuifolia: face abaxial (figura 24); escama (figura 26). Figura 25. T. lorentziana: face abaxial. Figura 27. T. usneoides: face abaxial. Figuras 28-29. Tillandsia sp: face abaxial (figura 28); escama (figura 29). (a = células centrais; $b=$ células pericentrais; $c=$ células subperiféricas; $d=$ células periféricas do escudo). Barras $=50 \mu \mathrm{m}(20-29)$.

Figures 20-29. Epidermis leaf surface view. 20-21. Tillandsia recurvata: abaxial epidermis (figure 20); scale (figure 21). 22. T. streptocarpa: abaxial epidermis. 23. T. mallemontii: abaxial epidermis, arrowhead: silica bodies. Figure 24, 26. T. tenuifolia: abaxial epidermis (figure 24); scale (figure 26). Figure 25. T. lorentziana: abaxial epidermis. Figure 27. T. usneoides: abaxial epidermis. Figures 28-29. Tillandsia sp: abaxial epidermis (figure 28); scale (figure 29). ( $\mathrm{a}=$ central cells; $\mathrm{b}=$ pericentral cells; $\mathrm{c}=$ subperipheral cells; $\mathrm{d}=$ peripheral cells $)$. Bars $=50 \mu \mathrm{m}(20-29)$. 

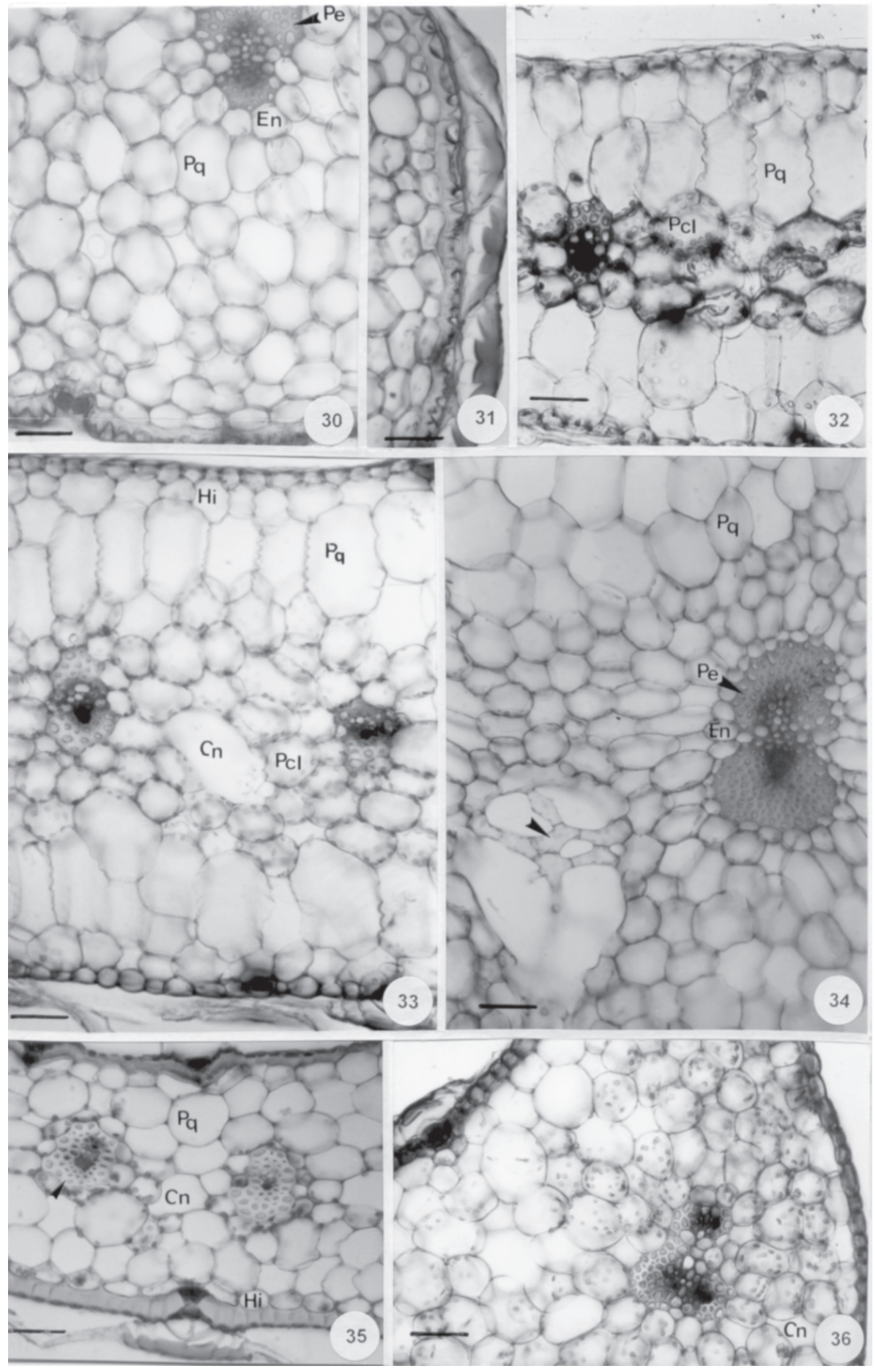

Figuras 30-36. Aspectos anatômicos de secções transversais da região mediana de folhas. 30-31. Tillandsia crocata: epiderme abaxial e mesofilo (figura 30); escamas epidérmicas da face abaxial (figura 31). 32. T. gardneri: epiderme e mesofilo. 33. T. geminiflora: epiderme e mesofilo. 34. T. lorentziana: mesofilo, cabeça-de-seta: células braciformes do canal de ar. 35. T. linearis: epiderme e mesofilo, cabeça-de-seta: fibras pericíclicas. 36. T. mallemontii: epiderme e mesofilo. $(\mathrm{Cn}=$ canal de ar; $\mathrm{En}=$ endoderme $; \mathrm{Hi}=$ hipoderme; $\mathrm{Pcl}=$ parênquima clorofiliano; $\mathrm{Pe}=$ periciclo; $\mathrm{Pq}=$ parênquima aqüífero). $\mathrm{Barras}=50 \mu \mathrm{m}$ 30-36). 
O mesofilo apresenta hipoderme pluriestratificada. Em Tillandsia crocata (figuras 30-31), T. linearis (figura 35), $T$. stricta (figuras 40, 55-56), $T$ tenuifolia (figuras 41-42) e Tillandsia sp. (figuras 45,60 ) o primeiro estrato da hipoderme apresenta-se constituído por células de paredes espessas, constituindo uma camada mecânica e são menores do que as células dos outros estratos. Nas demais espécies essas células apresentam paredes finas (figuras 32-33, 37, 43, 47, 50-52, 58). Os demais estratos constituem o parênquima aqüífero.

O segundo estrato da hipoderme, que corresponde ao parênquima aquífero, pode ser constituído por células arredondadas de paredes finas em Tillandsia crocata, T. lorentziana, $T$. linearis, $T$. mallemontii, T. recurvata, T. usneoides e Tillandsia sp. (figuras 30, 34-37, 43, 45 respectivamente), ou por células alongadas anticlinalmente em T. gardneri, T. geminiflora, T. streptocarpa, T. stricta e T. tenuifolia (figuras 32, $47,33,38,40,42,58$ respectivamente). As paredes das células desse estrato podem se apresentar sinuosas.

Em Tillandsia gardneri (figura 32), T. geminiflora (figura 33), T. stricta (figura 40) e T. tenuifolia (figura 42,58 ) as células do parênquima aquífero estão dispostas em paliçada. Em T. streptocarpa (figura 38) essas células se dispõem de forma concêntrica ao redor dos feixes vasculares, intercalando-se com o parênquima clorofiliano. Foram observados alguns cloroplastos em ambos os estratos da hipoderme, como mostrado em T. tenuifolia (figuras 57-58).

O parênquima clorofiliano localiza-se entre os feixes vasculares, numa faixa contínua em toda a extenção do limbo (figuras 1-12). É constituído por várias camadas de células de contorno arredondado e paredes finas, dispostas, por vezes, de forma bastante concêntrica ao redor dos feixes vasculares como na figura 34 .

Canais de ar também podem ocorrer na região mediana do mesofilo, entre os feixes vasculares, como em Tillandsia geminiflora (figura 33), T. lorentziana (figura 34) e T. linearis (figura 35). Geralmente esses canais se comunicam com as câmaras subestomáticas, como observado em $T$. gardneri (figura 48), T. stricta (figura 56) e Tillandsia sp. (Fig. 59). Os canais de ar do mesofilo são atravessados por diafragmas, constituídos de células braciformes (figura 34 - cabeça de seta). Foram observados idioblastos de ráfides no mesofilo de algumas espécies, como em T. geminiflora (figura 49).

O mesofilo apresenta feixes vasculares do tipo colateral em todas as espécies estudadas (figuras 30, 34, 36, 38, 45). Em $T$. crocata (figura 1), T. lorentziana (figura 5), T. streptocarpa (figura 8) e Tillandsia sp. (figura 12) os feixes vasculares maiores apresentam-se alternados com os menores e nas demais espécies eles são do mesmo tamanho (figuras 2-4, 6-7, 9-11). Esses feixes vasculares são envolvidos por bainha dupla. A externa é a endoderme e a interna são fibras pericíclicas, que ocorrem envolvendo total (figuras 35,50 ) ou parcialmente (figuras 30, 33-34) os feixes vasculares, formando calotas junto ao floema e ao xilema.

Características anatômicas das folhas das espécies estudadas foram sumarizadas na tabela 1, para facilitar a comparação entre as espécies e auxiliar na discussão.

\section{Discussão}

Segundo Benzing (1976), a subfamília Tillandsioideae apresenta a maioria de suas espécies epífitas, com formas de crescimento altamente especializadas e várias adaptações nos órgãos vegetativos. O autor classificou as Tillandsia como espécies que apresentam caracteres xeromórficos ao nível foliar. As Tillandsia estudadas neste trabalho são plantas epífitas com folhas xeromórficas que, através das escamas epidérmicas que recobrem o mesofilo, provavelmente captam água do ambiente, mostrandose altamente especializadas. Além das folhas, estruturas anatômicas de escapos dessas mesmas plantas também foram utilizadas com fins taxonômicos por Segecin \& Scatena (2004a). A capacidade adaptativa de rizomas e raízes dessas plantas, que é pouco comum para a família Bromeliaceae, foi mostrada por Segecin \& Scatena (2004b), relatando a presença de raízes intracorticais e comprovando a especialização dessas plantas ao hábito epifítico.

Pelo fato das folhas de Tillandsia apresentaremse recobertas por escamas epidérmicas e com mesofilo suculento, Schimper (1884 apud Benzing 1976), denominou estas espécies de epífitas atmosféricas

Figures 30-36. Leaf anatomy of Tillandsia. Cross sections at median region. 30-31. Tillandsia crocata: abaxial epidermis and lamina (figure 30); scales from abaxial epidermis (figure 31). 32. T. gardneri: epidermis and lamina. 33. T. geminiflora: epidermis and lamina. 34. T. lorentziana: lamina, arrowhead: braciform cells of the air canal. 35. T. linearis: epidermis and lamina, arrowhead: pericycle fibres. 36 . T. mallemontii: epidermis and lamina. $(\mathrm{Cn}=$ air canal; $\mathrm{En}=$ endodermis; $\mathrm{Hi}=$ hypodermis; $\mathrm{Pcl}=$ clorenchyma; $\mathrm{Pe}=$ pericycle $; \mathrm{Pq}=$ aqüiferous parenchyma). Barras $=50 \mu \mathrm{m} 30-36)$. 


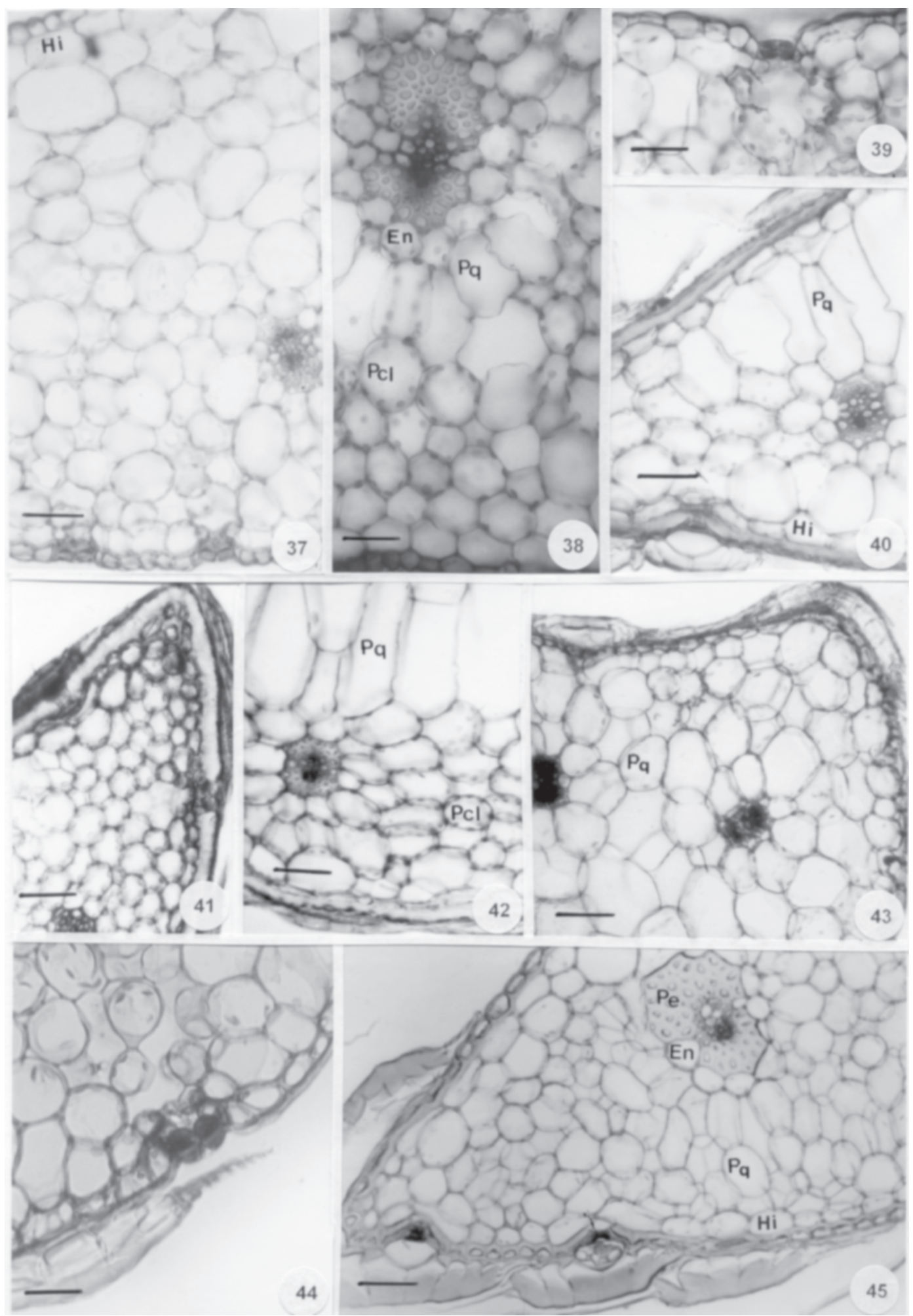

Figuras 37-45. Aspectos anatômicos de secções transversais da região mediana de folhas. 37. Tillandsia recurvata: epiderme e mesofilo. 38-39. T. streptocarpa: epiderme abaxial e mesofilo (figura 38); estômato da epiderme adaxial (figura 39). 40. T. stricta: epiderme e mesofilo. 41-42. T. tenuifolia: bordo foliar com estômato (figura 41); epiderme abaxial e mesofilo (figura 42). 4344. T. usneoides: epiderme adaxial e mesofilo (figura 43); estômato da epiderme abaxial (figura 44). 45. Tillandsia sp.: escamas epidérmicas e mesofilo. $(\mathrm{En}=$ endoderme; $\mathrm{Hi}=$ hipoderme; $\mathrm{Pcl}=$ parênquima clorofiliano; $\mathrm{Pe}=$ periciclo; $\mathrm{Pq}=$ parênquima aqǘfero). Barras $=50 \mu \mathrm{m}(37-45)$. 
extremas. Segundo Strehl (1983) as espécies epífitas atmosféricas extremas de Tillandsia apresentam o escudo das escamas epidérmicas assimétrico. No presente trabalho, a maioria das espécies estudadas apresentam escamas epidérmicas com escudos assimétricos, além da suculência resultante da presença de parênquima aquiífero. $\mathrm{O}$ prolongamento assimétrico dos escudos das escamas epidérmicas possivelmente aumenta a área de contato escudo/fluido, que pode aumentar a captação de água e nutrientes nele diluídos,

Tabela 1. Características anatômicas das folhas de Tillandsia L. dos Campos Gerais, PR, Brasil. $1=$ Tillandsia crocata (E. Morren) Baker, $2=$ T gardneri Lindl., $3=$ T. geminiflora Brongn., $4=$ T. linearis Vell., $5=$ T. lorentziana Griseb., $6=$ T. mallemontii Glaziou ex Mez. $7=$ T. recurvata L., $8=$ T. streptocarpa Baker, $9=$ T. stricta Soland. ex Sims., $10=$ T. tenuifolia L., $11=$ T. usneoides L., $12=$ Tillandsia $\mathrm{sp}$. $(\mathrm{x}=$ presença).

Table 1. Anatomical features of leaves of Tillandsia L. from "campos rupestres", Paraná State, Brazil. $1=$ Tillandsia crocata (E. Morren) Baker, $2=$ T gardneri Lindl., $3=$ T. geminiflora Brongn., $4=T$. linearis Vell., $5=$ T. lorentziana Griseb., $6=$ T. mallemontii Glaziou ex Mez. 7 = T. recurvata L., $8=$ T. streptocarpa Baker, $9=$ T. stricta Soland. ex Sims., $10=$ T. tenuifolia L., $11=$ T. usneoides L., $12=$ Tillandsia $\mathrm{sp} .(\mathrm{x}=$ presence $)$.

\begin{tabular}{lllllllllllll} 
Características & \multicolumn{11}{c}{ Espécies } \\
\cline { 2 - 10 } & 1 & 2 & 3 & 4 & 5 & 6 & 7 & 8 & 9 & 10 & 11 & 12 \\
\hline
\end{tabular}

Limbo

Folhas com limbo levemente curvado

Folhas com limbo curvo

Folhas com limbo côncavo-convexo

Folhas com limbo plano-convexo

Epiderme

Células epidérmicas de paredes espessadas

Cutícula lisa

Estômatos situados no mesmo nível que as demais células epidérmicas

Estômatos situados um pouco abaixo do nível das demais células epidérmicas

Escudo das escamas epidérmicas assimétrico

Escudo das escamas epidérmicas simétrico

Folha hipoestomática

Folha anfiestomática

Mesofilo

Parênquima aquífero constituído de células arredondadas

Parênq. aquífero constituído de céls. alongadas

Presença de canais de ar

Feixes vasculares todos do mesmo tamanho

Feixes vasculares maiores alternados com menores

Feixes vasculares parcialmente envolvidos por fibras pericíclicas

Feixes vasculares totalmente envolvidos por fibras pericíclicas

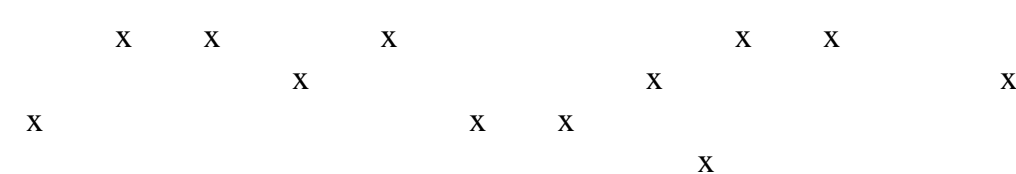

$\begin{array}{lllllllllll}\mathrm{x} & & & \mathrm{x} & \mathrm{x} & \mathrm{x} & \mathrm{x} & \mathrm{x} & \mathrm{x} & \mathrm{x} & \mathrm{x} \\ \mathrm{x} & \mathrm{x} & \mathrm{x} & \mathrm{x} & \mathrm{x} & \mathrm{x} & \mathrm{x} & \mathrm{x} & \mathrm{x} & \mathrm{x} & \mathrm{x} \\ & & & & & & & & & & \\ & \mathrm{x} & & & & & & & & & \end{array}$

$\begin{array}{llllllllllll}\mathrm{x} & & \mathrm{x} & \mathrm{x} & \mathrm{x} & \mathrm{x} & \mathrm{x} & \mathrm{x} & \mathrm{x} & & \mathrm{x} & \mathrm{x} \\ \mathrm{x} & \mathrm{x} & \mathrm{x} & & \mathrm{x} & \mathrm{x} & \mathrm{x} & \mathrm{x} & \mathrm{x} & & \mathrm{x} & \mathrm{x} \\ & & & \mathrm{x} & & & & & & \mathrm{x} & & \\ \mathrm{x} & \mathrm{x} & \mathrm{x} & \mathrm{x} & \mathrm{x} & \mathrm{x} & \mathrm{x} & & \mathrm{x} & \mathrm{x} & \mathrm{x} & \mathrm{x}\end{array}$

$\begin{array}{lllllllllllll}\mathrm{x} & & & \mathrm{x} & \mathrm{x} & \mathrm{x} & \mathrm{x} & & & & \mathrm{x} & \mathrm{x}\end{array}$

$\begin{array}{llllllllllllll}\mathrm{x} & \mathrm{x} & \mathrm{x} & \mathrm{x} & \mathrm{x} & \mathrm{x} & \mathrm{x} & \mathrm{x} & \mathrm{x}\end{array}$

$\begin{array}{llllllllllll} & \mathrm{x} & \mathrm{x} & \mathrm{x} & & \mathrm{x} & \mathrm{x} & & \mathrm{x} & \mathrm{x} & \mathrm{x} & \\ \mathrm{x} & & & & \mathrm{x} & & & \mathrm{x} & & & & \mathrm{x}\end{array}$

$\begin{array}{llllllllllll}\mathrm{x} & \mathrm{x} & \mathrm{x} & \mathrm{x} & \mathrm{x} & \mathrm{x} & \mathrm{x} & \mathrm{x} & \mathrm{x} & \mathrm{x} & \mathrm{x}\end{array}$

$\mathrm{X}$

Figures 37-45. Leaf anatomy of Tillandsia. Cross sections at median region. 37. Tillandsia recurvata: epidermis and lamina. 38-39. T. streptocarpa: abaxial epidermis and lamina (figure 38); stomata from adaxial epidermis (figure 39). 40. T. stricta: epidermis and lamina. 41-42. T. tenuifolia: stomata from the leaf margin (figure 41); abaxial epidermis and lamina (figure 42). 43-44. T. usneoides: adaxial epidermis and lamina (figure 43); stomata from abaxial epidermis (figure 44). 45. Tillandsia sp.: scales and lamina. $(\mathrm{En}=$ endodermis; $\mathrm{Hi}=$ hypodermis; $\mathrm{Pcl}=$ clorenchyma; $\mathrm{Pe}=$ pericycle; $\mathrm{Pq}=$ aqüiferous parenchyma). Bars $=50 \mu \mathrm{m}(37-45)$. 

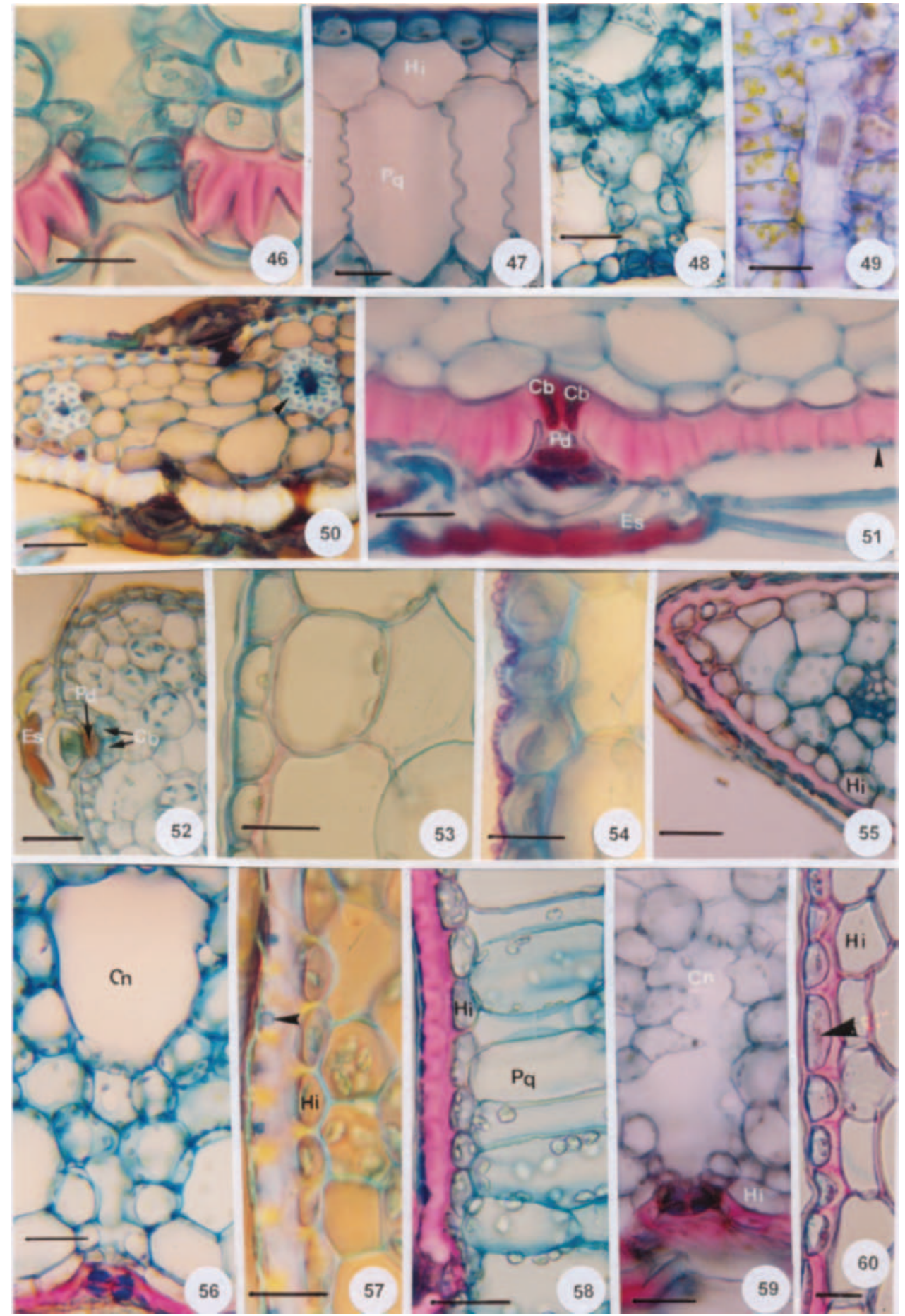

Figuras 46-60. Aspectos anatômicos de secções transversais e longitudinal da região mediana de folhas. 46. Tillandsia crocata: estômato abaxial. 47-48. T. gardneri: epiderme adaxial e mesofilo (figura 47); estômato abaxial (figura 48). 49. T. geminiflora: idioblasto contendo ráfide em secção longitudinal do mesofilo. 50-51. T. linearis: escamas epidérmicas do bordo, cabeça-de-seta: fibras pericíclicas (figura 50); detalhe da escama, cabeça-de-seta: lume celular (figura 51). 52. T. mallemontii: escama do bordo. 53. T. recurvata: epiderme abaxial e mesofilo. 54. T. streptocarpa: cutícula ornamentada. 55-56. T. stricta: bordo foliar (figura 55); estômato e lacuna de ar (figura 56). 57-58. T. tenuifolia: epiderme abaxial, cabeça-deseta: corpo de sílica (figura 57); face adaxial (figura 58). 59-60. Tillandsia sp.: estômato abaxial (figura 59); epiderme adaxial, cabeça-de-seta: corpos de sílica (figura 60$)$. $(\mathrm{Cb}=$ célula basal; $\mathrm{Cn}=$ canal de ar; $\mathrm{Es}=$ células do escudo; $\mathrm{Hi}=$ hipoderme; $\mathrm{Pd}=$ células do pedículo; $\mathrm{Pq}=$ parênquima aqüífero). Barras = $25 \mu \mathrm{m}(46-47,51,53-54,57-58) ; 50 \mu \mathrm{m}(48-50,52,55-56,59)$; $12,5 \mu \mathrm{m}(60)$. 
que estão disponíveis no ambiente atmosférico, como orvalho, neblina e chuva, conferindo à essas espécies sobrevivência em ambientes expostos diretamente ao sol e ventos constantes. Por essa razão, também denominamos as espécies de Tillandsia estudadas de epífitas atmosféricas extremas.

A presença de espessamento diferencial das paredes das células epidérmicas (exceto na parede periclinal externa) é marcante nas Bromeliaceae (Tomlinson 1969), e pode ser observada na maioria das espécies estudadas neste trabalho, além do espessamento das células da hipoderme. Esse espessamento epi e hipodérmico possivelmente atua diminuindo a evaporação de água dos tecidos, evitando o colapso das células pelo murchamento e garantindo, dessa forma, a sobrevivência das espécies em ambiente com condições abióticas extremas, como também foi relatado para outras espécies por Krauss (1948), Pyykkö (1966), Tomlinson 1969), Esau (1977) e Brighigna et al. (1984).

Algumas características como folhas hipoestomáticas (exceto T. streptocarpa Baker que é anfiestomática) e presença de sinuosidades nas paredes das células epidérmicas não condizem com o xeromorfismo predominante nas Tillandsia estudadas. De acordo com Fahn \& Cutler (1992) folhas hipoestomáticas são mais comuns em plantas de regiões úmidas do que secas, predominando folhas anfiestomáticas em regiões secas. O fato da maioria das espécies apresentarem estômatos apenas na face abaxial está mais ligado à possíveis relações filogenéticas de Bromeliaceae do que à problemas ecológicos. Para Pyykkö (1966) as ondulações e sinuosidades das paredes das células epidérmicas estão relacionados à ambientes úmidos, e de acordo com Haberlandt (1914) e Krauss (1948), as sinuosidades representam adaptações mecânicas, evitando o colapso das células durante os movimentos de expansão e contração da folha pela entrada e saída de água. Como as Tillandsia geralmente ocupam um ambiente com fornecimento descontínuo de água e nutrientes (Benzing 1990), talvez, no caso das espécies estudadas, a sinuosidade poderia auxiliar num suporte mecânico evitando murchamento. Tanto o hipoestomatismo quanto as paredes sinuosas podem ser resquícios evolutivos.

Além do espessamento das paredes das células epidérmicas, a presença de corpos de sílica nas espécies estudadas possivelmente contribui para a reflexão dos raios luminosos, intensos no habitat, evitando o aquecimento e a consequente perda de água dos tecidos internos, conforme foi citado por Baumert (1907 apud Krauss 1949) para outras espécies de Bromeliaceae. Segundo Tomlinson (1969), células epidérmicas com lume pequeno e portadoras de corpos de sílica são características de Bromeliaceae.

O mesofilo de todas as espécies estudadas apresenta parênquima aqüífero, o que confere suculência. Tietze (1906 apud Tomlinson 1969) observou nas espécies de Tillandsioideae de folhas estreitas, que o parênquima aqüífero é pouco desenvolvido, em virtude da água ser absorvida pelas escamas epidérmicas. Entretanto, nas espécies de Tillandsia aqui estudadas, mesmo naquelas que apresentam folhas com limbo estreito, o parênqüima aquífero é bem desenvolvido.

As espécies de Tillandsia estudadas apresentam mesofilo com parênquima aqüífero e parênquima clorofiliano diferenciados. Para Loeschen et al. (1993) esta característica é um indício de que as espécies apresentam metabolismo CAM, que se constitui numa adaptação em ambientes sujeitos a desidratação, devido a abertura estomática preferencialmente a noite, com consequiências positivas para a economia hídrica. Os autores referem-se a $T$. recurvata L. e T. usneoides L. como espécies portadoras de metabolismo CAM, o que pode ser corroborado pelo aspecto anatômico do mesofilo dessas espécies apresentado nos resultados deste trabalho.

Figures 46-60. Leaf anatomy of Tillandsia. Cross and longitudinal sections at median region. 46. Tillandsia crocata: abaxial stomata. 47-48. T. gardneri: adaxial epidermis and lamina (figure 47); abaxial stomata (figure 48). 49. T. geminiflora: idioblast with raphids in longitudinal section of lamina. 50-51. T. linearis: leaf margin scales, arrowhead: pericycle fibres (figure 50); scale detail, arrowhead: cell lumen (figure 51). 52. T. mallemontii: leaf margin scale. 53. T. recurvata: abaxial epidermis and lamina. 54. T. streptocarpa: button-like cuticle. 55-56. T. stricta: leaf margin (figure 55); stomata and air canal (figure 56). 5758. T. tenuifolia: abaxial epidermis, arrowhead: silica body (figure 57); adaxial epidermis (figure 58). 59-60. Tillandsia sp.: abaxial stomata (figure 59); adaxial epidermis, arrowhead: silica bodies (figure 60). ( $\mathrm{Cb}=$ basal cell; $\mathrm{Cn}=$ air canal; Es = shield cells; $\mathrm{Hi}=$ hypodermis; $\mathrm{Pd}=$ stalk cells; $\mathrm{Pq}=$ aqüiferous parenchyma). $\mathrm{Bars}=25 \mu \mathrm{m}(46-47,51,53-54,57-58) ; 50 \mu \mathrm{m}(48-50,52$, 55-56, 59); 12,5 $\mu \mathrm{m}$ (60). 
No presente estudo observaram-se diversas adaptações foliares que possibilitam a independência das espécies de Tillandsia estudadas do meio terrestre, contribuindo para o seu pronunciado epifitismo. A presença de escamas epidérmicas foliares, que absorvem água e nutrientes, representa uma dessas adaptações. As escamas epidérmicas também realizam efetiva regulação da intensidade luminosa, evitando a transpiração excessiva, através de uma diminuição da temperatura interna dos tecidos. Também formam uma cobertura sobre os estômatos para evitar a perda de água. Essas características também foram observadas em outras espécies do gênero por Picado (1913), Pittendrigh (1948), Benzing (1970), Benzing et al. (1976), e por Brighigna et al. (1984).

Deve-se ressaltar ainda a ocorrência de canais de ar no mesofilo das espécies de Tillandsia estudadas. De acordo com Meyer (1940), as raízes de Bromeliaceae realizam transporte de água por capilaridade através dos canais de ar. Brighigna et al. (1984) afirmam que as cavidades de ar que interrompem o parênquima clorofiliano da folha de Bromeliaceae auxiliam na evaporação, assegurando a eficiência fotossintética dessas plantas. Seguindo o raciocínio de Meyer (1940), para as espécies de Tillandsia estudadas, a água seria conduzida da raiz para as folhas por capilaridade, através dos canais de ar, e armazenada no parênquima aqüífero. Esta seria, então, uma estratégia eficiente de economia hídrica realizada por estas espécies.

Algumas estruturas anatômicas das Tillandsia estudadas, que foram discutidas acima, mostram a adaptação delas ao hábito epifítico e algumas são peculiares de determinadas espécies, que auxiliam na sua identificação taxonômica, conforme pode ser verificado na tabela 1 . Tillandsia usneoides L. pode ser identificada por apresentar limbo plano-convexo. Tillandsia streptocarpa Baker é a única espécie que apresenta cutícula ornamentada e folha anfiestomática. Tillandsia linearis Vell. é a única espécie que apresenta feixes vasculares totalmente envolvidos por fibras pericíclicas. As demais espécies apresentam estruturas anatômicas que formam agrupamentos por compartilhar mais de um caráter.

\section{Referências bibliográficas}

AMADO, F. G. M., ANDRADE, L. R., FARINA, M. \& MALM, O. 2002. Hg localisation in Tillandsia usneoides L. (Bromeliaceae), an atmospheric biomonitor. Atmospheric environment 36:881-887.
BARFUSS, M.H.J., SAMUEL, R., TILL, W. \& STUESSY, T. 2005. Phylogenetic relationships in subfamily Tillandsioideae (Bromeliaceae) based on DNA sequence data from seven plastid regions. American Journal of Botany 92:337-351.

BENZING, D. H. 1970. Foliar permeability and the absortion of minerals and organic nitrogen by certain tank bromeliads. Botanical Gazette 131:23-31.

BENZING, D.H. 1976. Bromeliad trichomes: structure, function, and ecological significance. Selbyana 1:330-348.

BENZING, D.H. 1990. Vascular epiphytes: General Biology and related biota. Cambridge University Press, New York.

BENZING, D.H. \& RENFROW, A. 1980. The nutritional dynamics of Tillandsia circinata in southern Florida and the origin of the air plant estrategy. Botanical Gazette 141:165-172.

BENZING, D. H., HENDERSON, K., KESSEL, B. \& SULAK, J. 1976. The absorptive capacities of bromeliad trichomes. American Journal of Botany 63:1009-1014.

BRAGA, M.M.N. 1977. Anatomia foliar de Bromeliaceae da campina. Acta Amazonica 7:1-74.

BRIGHIGNA, L., FIORDI, A. \& PALANDRI, M.R. 1984. Structural characteristcs of mesophyll in some Tillandsia species. Phytomorphology 34:191-200.

CRONQUIST, A. 1981. An integrated system of classification of flowering plants. Columbia University Press, New York.

DAHLGREN, R.M.T., CLIFFORD, H.T. \& YEO, P. F. 1985. The families of the monocotyledons. Springer-Verlag, Berlin.

ESAU, K. 1977. Anatomy of seed plants. John Wiley \& Sons, London.

FAHN, A. \& CUTLER, D.F. 1992. Xerophytes. Encyclopedia of plant taxonomy. Gebrüder Borntraeger, Berlin.

FIGUEIREDO, A.M.F., SAIKI, M., TICIANELLI, R.B., DOMINGOS, M., ALVES, E.S. \& MARKERT, B. 2001. Determination of trace elements in Tillandsia usneoides by neutron activation analysis for environmental biomonitoring. Journal of Radioanalytical and Nuclear Chemistry 249:391-395.

FIGUEIREDO, A.M.F., ALCALA, A.L., TICIANELLI, R.B., DOMINGOS, M. \& SAIKI, M. 2004. The use of Tillandsia usneoides L. as bioindicator of air pollution in São paulo, Brazil. Journal of Radioanalytical and Nuclear Chemistry 259:59-63.

HABERLANDT, G.F.J. 1914. Physiological plant anatomy. Mac Millan Co., London.

JOHANSEN, D.A. 1940. Plant microtechinique. MacGraw-Hill, New York.

JUDD, W.S., CAMPBELL, C.S., KELLOG, E.A., STEVENS, P.F. 1999. Plant Systematics. A phylogenetic approach. Sinauer Associates Inc., Massachusetts.

KRAUSS, B.H. 1948. Anatomy of the vegetative organs of the pineapple, Annanas comosus (L.) Merr. II. The leaf. Botanical Gazette 110:333-404.

LANGERON, M. 1949. Précis de Microscopie. Masson et Ciencie, Paris. 
LEME, E.M.C. \& MARIGO, L.C. 1993. Bromélias na natureza. Marigo Comunicação Visual Ltda, Rio de Janeiro.

LOESCHEN, V.S., MARTIN, C.E., SMITH, M. \& EDER, S.L. 1993. Leaf anatomy and $\mathrm{CO}_{2}$ recycling during crassulacean acid metabolism in twelve epiphytic epecies of Tillandsia (Bromeliaceae). International Journal of Plant Sciences 154:100-106.

MEYER, L. 1940. Zur Anatomie und Entwicklungsgeschichte der Bromeliaceenwurzeln. Planta 31:492-522.

PICADO, C. 1913. Sur les Broméliacées épiphytes considérées comme milieu biologique. Thesis, Paris.

PITTENDRIGH, C.S. 1948. The bromeliad-anopheles-malaria complex in Trinidad. I. The bromeliad flora. Evolution 2:58-89.

PROENÇA, S.L. \& SAJO, M.G. 2004. Estrutura foliar de espécies de Aechmea Ruiz \& Pav. (Bromeliaceae) do estado de São Paulo, Brasil. Acta Botanica Brasilica 18:319-331.

PYYKKÖ, M. 1966. The leaf anatomy of east Patagonian xeromorphic plants. American Journal of Botany 68:64-71.

ROBINSON, H. 1969. A monograph on foliar anatomy of the genera Connelia, Cottendorfia and Navia (Bromeliaceae). Smithsonian Contributions to Botany 2:1-41.

ROESER, K.R. 1962. Die nadel der Schwarzkiefer-masenprodukt und Keinstwert der Natur. Microkosmos 61:33-36.

SAJO, M.G., MACHADO, S.R. \& CARMELLO-GUERREIRO, S.M. 1998. Aspectos estruturais de folhas de bromélias e suas implicações no agrupamento de espécies. In Canistropsis. Bromélias da mata atlântica. (E.M.C. Leme, ed.). Salamandra, Rio de Janeiro, p.102-111.
SEGECIN, S. \& SCATENA, V.L. 2004a. Anatomia de escapos de Tillandsia L. (Bromeliaceae) dos Campos Gerais do Paraná, Brasil. Revista Brasileira de Botânica 27:515-525.

SEGECIN, S. \& SCATENA, V.L. 2004b. Morfoanatomia de rizoma e raízes de Tillandsia L. (Bromeliaceae) dos Campos Gerais, PR, Brasil. Acta Botanica Brasilica 18:253-260.

SOLEREDER, H. \& MEYER, F.J. 1929. Bromeliaceae. In Systematische Anatomie der Monokotyledonen. Gebrüder Borntraeger, Berlin, Heft IV, p.80-129.

SMITH, L.B. \& DOWNS, R.J. 1974. Pitcairnioideae (Bromeliaceae). Flora Neotropica Monographs 4:1-658.

SMITH, L.B. \& DOWNS, R.J. 1977. Tillandsioideae (Bromeliaceae). Flora Neotropica Monographs 4:663-1492.

SMITH, L.B. \& DOWNS, R.J. 1979. Bromelioideae (Bromeliaceae). Flora Neotropica Monographs 14:1604-1724.

STEVENS, P.F. 2001 onwards. Angiosperm Phylogeny Website. Version 3, May 2002. http://www.mobot.org/ MOBOT/research/Apweb/.

STREHL, T. 1983. Forma, distribuição e flexibilidade dos tricomas foliares usadas na filogenia de bromeliáceas. Iheringia Serie Botanica 31:105-119.

TOMLINSON, P.B. 1969. III - Commelinales-Zingiberales. In Anatomy of the Monocotyledons (C.R. Metcalfe, ed.). Clarendon Press, Oxford, v.3, p.1-446. 